\title{
Fitoquímica e atividade antifúngica do extrato de folhas de Piper marginatum no controle de fitopatógenos
}

O emprego de extratos vegetais com potencial antifúngico pode ser uma opção para reduzir o uso de agroquímicos, evitar problemas ambientais, bem como a resistência de fitopatógenos. Objetivou-se caracterizar quimicamente e avaliar a atividade antifúngica do extrato etanólico de folhas da espécie Piper marginatum sobre os fungos fitopatogênicos Alternaria sp e Colletotrichum musae. O extrato etanólico foi obtido via Soxhlet, e o perfil químico caracterizado por Cromatografia em Camada Delgada (CCD). Nos ensaios antifúngicos, o extrato foi diluído em meio de cultura batata-dextrose-ágar (BDA) para obtenção das concentrações 10\%, $20 \%, 30 \%, 40 \%$ e $50 \%$ e vertidos em placas de Petri contendo BDA, para deposição dos fitopatógenos após solidificação. O controle consistiu do semeio dos fungos em meio sem adição dos extratos. Os fitopatógenos Alternaria sp. e C. musae foram obtidos de eucalipto e banana. O delineamento experimental foi inteiramente casualizado (DIC) em esquema fatorial com quatro repetições. As avaliações foram realizadas medindo-se o diâmetro médio das colônias diariamente, durante cinco dias. A identificação do perfil cromatográfico de P. margintatum evidenciou a presença de taninos hidrolisáveis, fenilpropanoides, flavonoides e terpenoides. O fitopatógeno mais sensível à ação do extrato foi C. musae, a partir da concentração de $10 \%$. As concentrações de 40 e $50 \%$ foram responsáveis por reduções de $10,9 \%$ e $20,2 \%$ no crescimento micelial deste fungo. Com isso, o extrato etanólico de Piper marginatum, pode ser considerado promissor para produção de um antifúngico natural na redução do uso de agroquímicos.

Palavras-chave: Controle alternativo; Extrato; Piper marginatum; Colletotrichum musae; Alternaria sp..

\section{Phytochemistry and antifungal activity of Piper marginatum leaf extract in the control of phytopathogens}

\begin{abstract}
The use of plant extracts with antifungal potential may be an option to reduce the use of agrochemicals, avoid environmental problems as well as the resistance of phytopathogens. The objective was to chemically characterize and evaluate the antifungal activity of the ethanolic extract of Piper marginatum leaves on phytopathogenic fungi Alternaria sp. and Colletotrichum musae. The ethanolic extract was obtained via Soxhlet, and the chemical profile characterized by Thin Layer Chromatography (CCD). In antifungal assays, the extract was diluted in potato-dextrose-agar (BDA) culture medium to obtain $10 \%, 20 \%, 30 \%, 40 \%$ and $50 \%$ concentrations and poured into BDA-containing Petri dishes for deposition of the extracts. phytopathogens after solidification. The control consisted of the sowing of the fungi in medium without addition of the extracts. Plant pathogens Alternaria sp. and C. musae were obtained from eucalyptus and bananas. The experimental design was completely randomized in a factorial scheme with four replications. Evaluations were performed by measuring the average diameter of the colonies daily for five days. The identification of P. margintatum chromatographic profile showed the presence of hydrolysable tannins, phenylpropanoids, flavonoids and terpenoids. The phytopathogen most sensitive to the action of the extract was C. musae, from the concentration of $10 \%$. The concentrations of 40 and $50 \%$ were responsible for reductions of $10,9 \%$ and $20,2 \%$ in the mycelial growth of this fungus. With this, the ethanolic extract of Piper marginatum can be considered promising for the production of a natural antifungal in reducing the use of agrochemicals.
\end{abstract}

Keywords: Alternative control; Extract; Piper marginatum; Colletotrichum musae; Alternaria sp.

Topic: Microbiologia Agrícola e Ambiental

Received: 07/08/2018

Reviewed anonymously in the process of blind peer.
Approved: 17/08/2018
Caroline Gomes Macêdo (iD)

Universidade Federal do Pará, Brasil

http://lattes.cnpq.br/1637502954956396

http://orcid.org/0000-0003-3715-1307

carolgomesmacedo@hotmail.com

Bruna Cristine Martins de Sousa

Universidade Federal do Oeste do Pará, Brasil

http://lattes.cnpq.br/2995856324286537

bruna0909martins@hotmail.com

\section{Sidney Santos Fraga (iD)}

Universidade Federal do Oeste do Pará, Brasil http://lattes.cnpq.br/9282514002226634 http://orcid.org/0000-0002-3831-6639

sidneyssf643@gmail.com

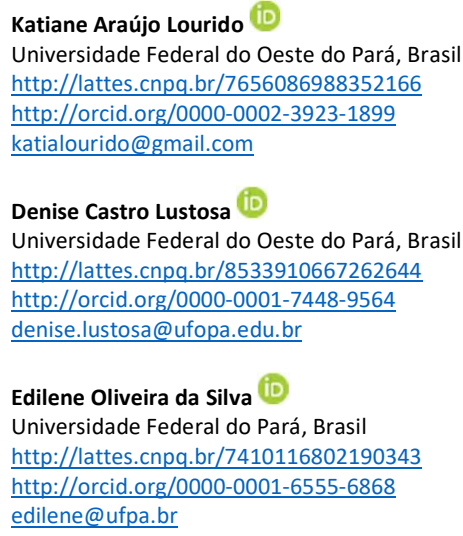

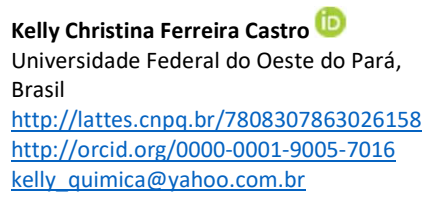

\section{Referencing this:}

MACÊDO, C. G.; SOUSA, B. C. M.; FRAGA, S. S.; LOURIDO, K. A.; LUSTOSA, D. C.; SILVA, E. O.; CASTRO, K. C. F.. Fitoquímica e atividade antifúngica do extrato de folhas de Piper marginatum no controle de fitopatógenos. Revista Ibero-Americana de Ciências Ambientais, v.9, n.6, p.70-77, 2018. DOI: http://doi.org/10.6008/CBPC21796858.2018.006.0009 


\section{INTRODUÇÃO}

A sociedade vem se preocupando cada vez mais com o uso intensivo e indiscriminado de produtos químicos que causam diversos problemas ao meio ambiente e ao homem, como a contaminação de águas, solos, animais e alimentos; a intoxicação de agricultores; a eliminação de microrganismos responsáveis pela degradação da matéria orgânica ou de organismos utilizados em programas de controle biológico. Também se verifica uma crescente resistência de fitopatógenos, pragas e plantas daninhas a produtos químicos (SPADOTTO et al., 2004).

O controle de doenças causadas por fungos fitopatogênicos é realizado quase que exclusivamente com aplicações de agroquímicos de alta periculosidade, provocando diversos problemas ambientais e resistência dos patógenos a esses produtos. Assim, o emprego de extratos vegetais com potencial antifúngico pode ser uma opção para reduzir o uso de defensivos (SCHWAN-ESTRADA et al., 2003). Em relação à utilização do controle químico, um dos maiores perigos representados diz respeito aos efeitos que eles podem provocar na saúde das pessoas, principalmente daquelas que, no campo ou na indústria, ficam expostas ao contato direto com os agrotóxicos (LONDRES, 2011).

A busca crescente por produtos que apresentem baixa toxicidade ao homem, menor impacto ambiental e menores custos de aquisição vem fazendo crescer a utilização dos recursos naturais renováveis como fonte de novas substâncias bioativas (KIM et al., 2003; MENEZES, 2005; PANG et al., 2012). Dentre os métodos alternativos de controle, a utilização de extratos e óleos essenciais de plantas medicinais pode ser uma opção viável, em relação do ponto de vista econômico e principalmente ambiental (RODRIGUES et al., 2006).

O controle alternativo de doenças em plantas com óleos e extratos vegetais já foi relatado por alguns autores, como Venturoso et al. (2011), que verificou, in vitro, atividade antifúngica de extratos aquosos de cravo-da-índia, alho e canela sobre os fitopatógenos Aspergillus sp., Penicillium sp., Colletotrichum sp., Phomopsis sp., Fusarium solani e Cercospora kikuchii; Carnelossi et al. (2009), que constatou potencial dos óleos essenciais de Cymbopogon citratus, Eucalyptus citriodora, Mentha arvensis e Artemísia dracunculus no controle de Colletotrichum gloeosporioides em frutos de mamão, e Silva et al. (2007), que observou atividade antifúngica de óleos essenciais de Piper callosum, Piper marginatum var. anisatum e Piper enckea sobre Moniliophthora perniciosa, Phytophthora palmivora e Phytophthora capsici.

O gênero Piper possui um grande número de espécies conhecidas popularmente como Pariparoba. No Brasil, cerca de 266 dessas espécies habitam lugares úmidos, quentes, várzeas de florestas tropicais e todos os tipos de vegetação, principalmente, a vegetação conhecida como pioneira (KATO et al., 2007). Esse gênero possui importância econômica através das indústrias farmacêuticas, alimentícia e de inseticidas, tendo em vista o seu uso terapêutico em diversas doenças, além de interesse comercial por meio da produção de óleos essenciais (MAIA et al., 1987; MESQUITA et al., 2005; REIGADA, 2009; SANTOS et al., 2001). A Piper nigrum, por exemplo, é uma espécie bastante difundida comercialmente pela produção de pimenta-do-reino através do fruto, sendo usada na culinária mundial como especiaria (SRINIVASAN, 2007). 
Os estudos fitoquímicos das espécies de Piper têm levado ao isolamento de uma variedade de compostos fisiologicamente ativos pertencentes a diferentes classes de metabólitos secundários, tais como alcaloides, amidas, propenilfenóis, ligninas, neoligninas, terpenos, esteroides, kavalactonas, piperolidinas, chalconas, diidrochalconas, flavonas e flavononas, apresentando importantes atividades biológicas para este gênero (PARMAR et al., 1997).

A flora da Amazônia é bastante diversificada e em parte constituída por espécies nativas com características peculiares. Dentre essas, destaca-se P. marginatum Jacq, conhecida popularmente como malvaísco, caapeba cheirosa, nhandi, nhandú, pimenta-do-mato e pimenta-dos-índios (GUIMARÃES et al., 2004). Ocorre nas Índias Ocidentais, América Central e na América do Sul, e no Brasil encontra-se nos estados do Amazonas, Pará, Ceará, Paraíba e Pernambuco (YUNCKER, 1972; GUIMARÃES et al., 2004). Abundante na Amazônia, $P$. marginatum é amplamente utilizada na medicina popular contra gonorreia, problemas da vesícula, tosse, baques, erisipela, queimaduras, dor de cabeça, gripe, furúnculos, alívio de dor, inchaço, inflamação das pernas, desinfetar e cicatrizar feridas, calmante, no tratamento de doenças do baço e fígado, como diurético, no tratamento de picadas de cobra e insetos, ação antiespasmódica (PEREIRA et al., 2007).

Estudos fitoquímicos com espécies de Piper demonstram uma grande diversidade de metabólitos secundários, inclusive com ação antifúngica (REIGADA et al., 2007; JOHNNY et al., 2011). Porém, poucas informações foram encontradas sobre a espécie $P$. marginatum, nativa do estado do Pará, e extração de seus compostos utilizando como solvente o etanol, que segundo Capello et al. (2007), é menos tóxico, biodegradável e ocasiona menor poluição ao meio ambiente em relação aos outros tipos de solventes. Diante do exposto, objetivou-se avaliar a composição química e a atividade antifúngica do extrato etanólico de folhas da espécie $P$. marginatum sobre Alternaria sp. e Colletotrichum musae.

\section{METODOLOGIA}

Para a obtenção do extrato etanólico, folhas de P. marginatum, conhecida popularmente como Cabeba-cheirosa, Nhandi, Pimenta-do-mato e Pimenta-dos-índios, foram coletadas em área de mata natural, situada na Universidade Federal do Oeste do Pará - UFOPA, no município de Santarém (PA) no período seco, mês de novembro, das $17 \mathrm{~h}$ às $18 \mathrm{~h}$. O material vegetal foi identificado botanicamente e depositado no Herbário da UFOPA, sob o registro HSTM - no 00370.

As folhas foram secas em estufa de circulação de ar a $40^{\circ} \mathrm{C}$ durante 3 dias, e posteriormente trituradas, pesadas $(83 \mathrm{~g})$ e submetidas a extração via Soxhlet para obtenção do extrato etanólico bruto, por um período de quatro horas. Após evaporação do solvente, o extrato foi armazenado em frasco âmbar, devidamente identificado e acondicionado sob refrigeração à $-10^{\circ} \mathrm{C}$. O rendimento do extrato foi obtido por meio da fórmula: [Massa do extrato $(\mathrm{g}) /$ Massa do material seco $(\mathrm{g})$ ] x 100.

O extrato etanólico de $P$. marginatum foi submetido a análise de cromatografia de camada delgada (CCD), para a obtenção perfil químico preliminar a fim de se avaliar as possíveis classes de substâncias como: taninos hidrolisáveis, cumarinas, terpenos e flavonóides. O extrato foi dissolvido em metanol correspondendo a uma concentração de $20 \mathrm{mg} / \mathrm{mL}$. Utilizou-se como fase móvel três sistemas de eluição: 
Acetato de etila: Ácido fórmico: Ácido acético glacial: Água (AAAA) e Hexano: Acetato de etila: Ácido fórmico (HAA) e empregando como fase estacionária placas de alumínio TLC com fluorescência, de sílica gel 60 da Macherey-Nagel com área total de $50 \mathrm{~cm}^{2}$.

Após a eluição do extrato nas placas cromatográficas, as manchas foram visualizadas em câmara de fluorescência com luz ultravioleta (UV) em 254 e 360nm e, em seguida, como reagente revelador utilizou-se Hidróxido de potássio $(\mathrm{KOH})$ a $5 \%(\mathrm{~m} / \mathrm{v})$, Difenilboriloxietilamina $(\mathrm{NP})$ a $1 \%(\mathrm{~m} / \mathrm{v})$, Vanilina sulfúrica à $1 \%$ $(\mathrm{m} / \mathrm{v})$ e Cloreto férrico a $1 \%(\mathrm{~m} / \mathrm{v})$, para cada classe de substâncias. Para a efetivação das reações com os reagentes reveladores específicos, para as classes de substâncias taninos e terpenos, submeteu-se cada placa em chapa de aquecimento a $100^{\circ} \mathrm{C}$ para revelar substâncias orgânicas presentes. Os resultados obtidos foram comparados com os padrões de referência, segundo metodologia adaptada por Wagner \& Bladt (2001).

$\mathrm{Na}$ avaliação da atividade antifúngica do extrato de Cabeba-cheirosa foram utilizados os fungos fitopatogênicos Alternaria sp. e C. musaeprovenientes de folhas de eucalipto e frutos de banana, respectivamente, dos quais foram obtidas colônias axênicas para utilização no ensaio. Foram preparadas soluções contendo o extrato de $P$. marginatum e água destilada esterilizada, na proporção 1:1, sendo adicionado Polivinilpirrolidona (PVP), na concentração 1:4 (extrato: PVP). As soluções foram filtradas em membrana de Millipore ${ }^{\circledR}(0,22 \mu \mathrm{m})$, e colocadas em meio Batata-Dextrose-Ágar (BDA), fundente (aproximadamente $45^{\circ} \mathrm{C}$ ), para obtenção das seguintes concentrações: $10 \%$; $20 \%$; 30\%; 40\% e 50\%.

Após a adição do extrato etanólico de $P$. marginatum, os meios foram homogeneizados e vertidos em placas de Petri, onde depositou-se, centralmente, um disco $(4 \mathrm{~mm})$ de BDA por placa, contendo as estruturas dos seus respectivos fitopatógenos (PINTO et al., 2003). O tratamento controle consistiu do cultivo dos fungos em BDA sem adição do extrato. Os fungos foram incubados a $25^{\circ} \mathrm{C}$, sob fotoperíodo de $12 \mathrm{~h}$. $\mathrm{O}$ delineamento experimental foi inteiramente casualizado (DIC), em esquema fatorial, com quatro repetições. As avaliações foram realizadas medindo-se o diâmetro médio das colônias, diariamente, durante cinco dias. Os dados foram submetidos à ANOVA, comparando-se as médias pelo teste de Tukey a $5 \%$ de probabilidade, utilizando-se o software estatístico Sisvar 5.6.

\section{DISCUSSÃO TEÓRICA}

O rendimento do extrato etanólico de $P$. marginatum, a partir de $83 \mathrm{~g}$ de folhas secas e trituradas foi de $21,4 \%$. Os resultados do perfil químico por CCD do extrato de $P$. marginatum evidenciaram a presença de taninos hidrolisáveis, flavonoides, terpenos e a ausência de cumarinas (tabela 1). Para o ensaio antifúngico, verificou-se diferença significativa tanto para os fatores isoladamente (fitopatógenos e concentrações), bem como para a interação entre eles $(p \leq 0,05)$. Em relação ao fator fitopatógenos, C. musae sp. foi o mais sensível ao extrato de $P$. marginatum, conforme se nota na figura 1 , com redução de $1,5 \mathrm{~cm}$ no diâmetro médio das colônias em relação a Alternaria sp.

Tabela 1: Classes de substâncias do extrato etanólico de folhas de P. marginatum por CCD. 


\begin{tabular}{|l|c|c|}
\hline Taninos hidrolisáveis & + & +++ \\
\hline Cumarinas & - & - \\
\hline Flavonoides & + & ++ \\
\hline Terpenoides & + & + \\
\hline
\end{tabular}

Legenda: Presença (+); Ausência (-); Forte (+++); Moderada (++); Fraco (+).

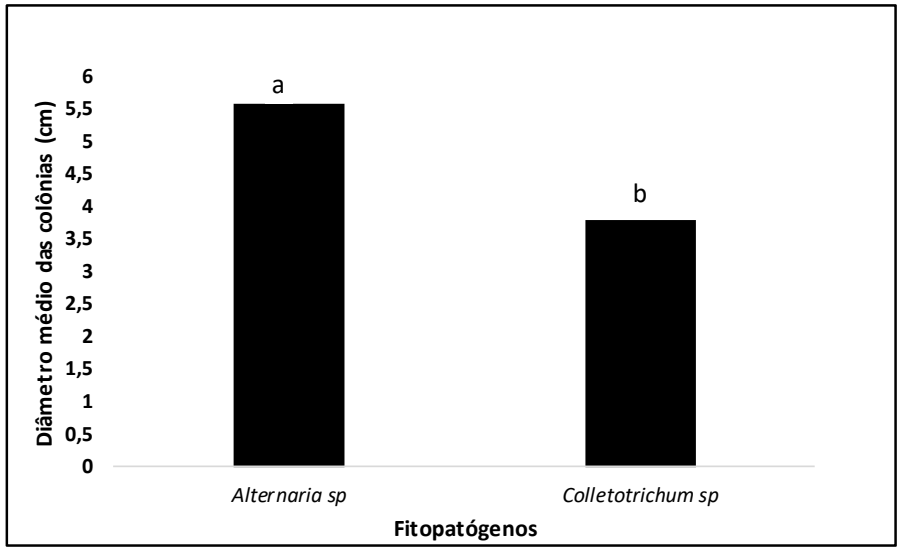

Figura 2: Diâmetro médio das colônias dos fitopatógenos submetidos ao extrato da Piper marginatum. Médias seguidas pelas mesmas letras nas colunas não diferem entre si pelo teste de Tukey $(p \leq 0,05)$.

Considerando as concentrações do extrato etanólico de $P$. marginatum, verificou-se uma linearidade na redução do diâmetro médio das colônias com o aumento das concentrações, ilustrada na figura 2. A concentração de 50\% proporcionou melhor ação antifúngica, com redução de $11,5 \%$ em relação ao controle. Analisando a interação entre os fatores (fitopatógenos x concentrações), apenas a concentração de 50\% reduziu o diâmetro médio da colônia de Alternaria sp., em relação ao controle. Enquanto que, C. musae teve seu crescimento diminuído, em relação ao tratamento controle, em todas as concentrações analisadas, diferindo também do fungo Alternaria sp. (tabela 2). As concentrações de $40 \%$ e $50 \%$ ocasionaram reduções de $10,9 \%$ e $20,2 \%$, respectivamente, no crescimento micelial do isolado fúngico obtido dos frutos de banana. Médias seguidas pelas mesmas letras minúsculas nas colunas e pelas mesmas letras maiúsculas nas linhas não diferem entre si pelo teste de Tukey $(p<0,01)$.

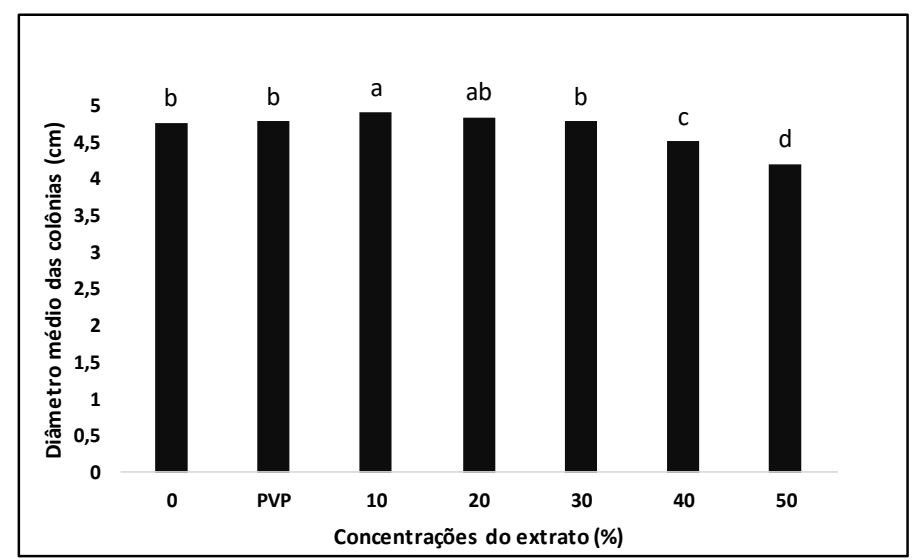

Figura 3: Diâmetro médio das colônias dos fitopatógenos submetidos às diferentes concentrações do extrato de Piper marginatum. Médias seguidas pelas mesmas letras nas colunas não diferem entre si pelo teste de Tukey $(p \leq 0,05)$.

Tabela 2: Diâmetro médio das colônias de Alternaria sp. e Colletotrichum musae submetidos ao extrato etanólico de Piper marginatum, em diferentes concentrações.

\begin{tabular}{|l|c|c|c|c|c|c|c|}
\hline \multirow{3}{*}{ Fitopatógenos } & \multicolumn{7}{|c|}{ Diâmetro médio das colônias (cm) } \\
\cline { 2 - 8 } & \multicolumn{7}{|c|}{ Concentrações do extrato (\%) } \\
\cline { 2 - 8 } & Controle & PVP & 10 & 20 & 30 & 40 & 50 \\
\hline Alternaria sp. & $5,42 \mathrm{aBC}$ & $5,52 \mathrm{aB}$ & $5,87 \mathrm{aA}$ & $5,85 \mathrm{aA}$ & $5,82 \mathrm{aA}$ & $5,37 \mathrm{aC}$ & $5,15 \mathrm{aD}$ \\
\hline
\end{tabular}




\begin{tabular}{|l|c|c|c|c|c|c|c|}
\hline Colletotrichum sp. & $4,10 \mathrm{bA}$ & $4,05 \mathrm{bAB}$ & $3,92 \mathrm{bCB}$ & $3,85 \mathrm{bCD}$ & $3,75 \mathrm{bDE}$ & $3,65 \mathrm{bE}$ & $3,27 \mathrm{bF}$ \\
\hline $\mathbf{C V}(\%)$ & \multicolumn{7}{|l|}{} \\
\hline
\end{tabular}

Legenda: PVP: Polivinilpirrolidona.

A flora da Amazônia é bastante diversificada e em parte constituída por espécies nativas com características peculiares. Dentre essas, destaca-se $P$. marginatum Jacq., conhecida popularmente como malvaísco, caapeba cheirosa, nhandi, nhandú, pimenta-do-mato e pimenta-dos-índios; encontra-se distribuída na América do Sul, na América Central e nas Antilhas; no Brasil, a espécie é encontrada em toda Região Norte (GUIMARÃES et al., 2004).

Pesquisas existentes de extratos oriundos das folhas de $P$. marginatum apontam para outras técnicas de extração, como por exemplo, maceração à frio, agitação constante, além da utilização de solventes de diferentes polaridades (ARAÚJO et al., 2014; DUARTE et al., 2004), o que dificulta a comparação com a literatura sobre rendimento. A espécie $P$. arboreum, quando submetida ao mesmo método de extração, apresentou um rendimento de apenas 6,9\% (FIGUEREDO et al., 2014), sendo inferior ao obtido na espécie $P$. marginatum.

O perfil fitoquímico das espécies de Piper apresenta-se muito diversificado, sendo isolados compostos pertencentes às mais diferentes classes de metabólitos secundários, incluindo amidas, lignanas, hidroquinonas, neolignanas, alcaloides, terpenos, derivados do ácido benzoico e aristolactamas (PARMAR et al., 1997; YAMAGUCHI et al., 2006), corroborando com os resultados encontrados neste trabalho. A presença ou ausência de metabólitos secundários também pode ser atribuídas a fatores ligados à estímulos ambientais como: sazonalidade, temperatura, disponibilidade hídrica, nutrientes presentes no solo, entre outros (GOBBO-NETO et al., 2007).

Araújo et al. (2014) verificou inibição no crescimento micelial de Colletotrichum scovillei pelo extrato metanólico de P. marginatum; os resultados encontrados neste trabalho com o extrato etanólico desta espécie sobre Colletotrichum musae também foram significativos. Espécies do gênero Piper já foram testados contra alguns fitopatógenos in vitro. Silva et al. (2007) avaliou os óleos essenciais de Piper callosum, $P$. marginatum var. anisatum e Piper enckea sobre Moniliophthora perniciosa, Phytophthora palmivora e Phytophthora capsici, constatando que os óleos de P. callosum e P. enckea foram mais efetivos; Extrato de Piper chaba inibiu o crescimento micelial de Fusarium oxysporum, P. capsici, Colletotrichum capsici, F. solani e Rhizoctonia solani (RAHMAN et al., 2011).

Santos et al. (2014), avaliando o extrato de aroeira (Schinus terebinthifolius), in vitro, observou efeito fungitóxico capaz de inibir o desenvolvimento de diversos fungos, incluindo C. gloeosporioides, porém, testando o extrato aquoso e o hidrolato de sementes dessa espécie, os efeitos não foram favoráveis, em nenhuma das concentrações, no combate a este fungo em goiaba. Rozwalka (2008) observou que o extrato aquoso de cancorosa (Jodina rhombifolia) inibiu em apenas 9,07\% o crescimento de Colletotrichum gloeosporioides demonstrando baixa eficiência desse extrato quando comparado ao obtido de cravo-da-índia (Syzygium aromaticum), que inibiu em 100\% o crescimento do fungo, em meio BDA, na concentração de $10 \%$. 
Ranasinghe et al. (2002), utilizou as plantas medicinais cravo-da-índia e canela (Cinnamomum zeylanicum) que apresentaram efeito fungistático e fungicida contra Colletotrichum musae e Fusarium proliferatum, ambos patógenos da bananeira. Os resultados encontrados para o fungo Alternaria sp. devese ao fato que, os metabólitos secundários obtidos de plantas podem afetar de forma distinta os diferentes fitopatógenos, até mesmo espécies dentro de um mesmo gênero.

Além de permitir a aquisição de conhecimentos sobre os efeitos positivos das plantas medicinais, os resultados podem contribuir para a manutenção do equilíbrio ambiental e de uma agricultura mais sustentável. Que irão ajudar positivamente na redução de perdas na produção agrícola, redução de problemas relacionados à intoxicação alimentar, causado pelos fitopatógenos e principalmente redução na contaminação das águas subterrâneas e superficiais, da atmosfera e dos solos

\section{CONCLUSÕES}

O extrato etanólico de $P$. margintatum apresentou taninos hidrolisáveis, fenilpropanoides, flavonoides e terpenoides na sua composição química. Foi observada atividade antifúngica sobre o fitopatógeno $C$. musae, em todas as concentrações testadas. Estes resultados viabilizam a realização de fracionamentos e ensaios in vitro e in vivo, visando a identificação e isolamento dos compostos bioativos para a formulação de produtos alternativos no controle da antracnose.

\section{REFERÊNCIAS}

ARAÚJO, E. R.; HARAND, W.; LIMA, I. C.; DIAS, F. C. R.; SANTANA, A. A. D.; CARVALHO, R. R. C.; LARANJEIRA, D.. Extratos de Piper marginatum e Azadirachta indica no controle de Colletotrichum scovillei em pimentão. Pesquisa Agropecuária Brasileira, v.49, n.2, p.88-94, 2014. DOI: http://doi.org/10.1590/S0100-204X2014000200002

CAPELLO C.; FISCHER, U.; HUNGERBUHLER, K.. What is a green solvent? A comprehensive framework for the environmental assessment of solventes. Green Chemistry, v.9, p.927-934, 2007. DOI: http://doi.org/10.1039/B617536H

CARNELOSSI, P. R.; SCHWAN-ESTRADA, K. R. F.; CRUZ, M. E. S.; ITAKO, A. T.; MESQUINI, R. M.. Óleos essenciais no controle pós-colheita de Colletotrichum gloeosporioides em mamão. Revista Brasileira de Plantas Medicinais, v.11, n.4, p.399-406, 2009.

DUARTE, M. C. T.; FIGUEIRA, G. M.; PEREIRA, B.; MAGALHÃES, P. M.; DELARMELINA, C.. Atividade antimicrobiana de extratos hidroalcoólicos de espécies da coleção de plantas medicinais CPQBA/UNICAMP. Revista Brasileira de Farmacognosia, v.14, p.6-8, 2004.

FIGUEREDO, F. G.; TINTINO, S. R.; BRITO, D. I. V.; BRAGA, M. F. B. M.; LEITE, N. F.; LUCENA, B. F. F.; SOBRAL-SOUSA, C. E.; GOMEZ, M. C. V.; COUTINHO, H. D. M.. Avaliação das potenciais atividades tripanocida e antileishmania do extrato de folhas de Piper arboreum (Piperaceae) e de suas frações. Revista de Ciências Farmacêuticas Básica e Aplicada, v.35, n.1, p.149-154, 2014.
GOBBO-NETO, L.; LOPES, N. P.. Plantas medicinais: fatores de influência no conteúdo de metabólitos secundários. Química Nova, v.30, n.2, p.374-381, 2007.

GUIMARÃES, E. F.; GIORDANO, L. C. D. S.. Piperaceae do Nordeste brasileiro: estado do Ceará. Rodriguésia, v.55, n.84, p.21-46, 2004.

JOHNNY, L.; YUSUF, U. K.; NULIT, R.. Antifungal activity of selected plant leaves crude extracts against a pepper anthracnose fungus, Colletotrichum capsici (Sydow) butler and bisby (Ascomycota: hyllachorales). African Journal of Biotechnology, v.10, p.4157-4165, 2011. DOI: https://doi.org/10.5897/AJB10.2085

KATO, M. J.; FURLAN, M.. Chemistry and evolution of the Piperaceae. Pure and Applied Chemistry, v.79, n.4, p.529538, 2007. DOI: https://doi.org/10.1351/pac200779040529

KIM, S. I.; ROH, J. Y; KIM, D. H.; LEE, H. S.; AHN, Y. J.. Insecticidal activities of aromatic plant extracts and essential oils against Sitophilus oryzae and Callosobruchus chinensis. Journal of Stored Products Research, v.39, n.3, p.293-303, 2003. DOI: http://doi.org/10.1016/S0022-474X(02)00017-6

LONDRES, F.. Agrotóxicos no Brasil: um guia para ação em defesa da vida. Rio de Janeiro: 2011.

MAIA, J. G. S.; SILVA, M. L.; LUZ, A. I. R.; ZOGHBI, M. G. B.; RAMOS, L. S.. Espécie de Piper da Amazônia Ricas em Safrol. Química Nova, p.200-204, 1987. 
MENEZES, E. L. A.. Inseticidas botânicos: seus princípios ativos, modo de ação e uso agrícola. Seropédica: Embrapa, 2005.

MESQUITA, J. M. O.; CAVALEIRO, C.; CUNHA, A. P.; LOMBARDI, J. A.; OLIVEIRA, A. B.. Estudo comparativo dos óleos voláteis de algumas espécies de Piperaceae. Revista Brasileira de Farmacognosia, v.15, n.1, p.6-12, 2005. DOI: http://doi.org/10.1590/S0102-695X2005000100003

PANG, Y. P.; BRIMIJOIN, S.; RAGSDALE, D. W.; ZHU, K. Y.; SURANYI, R.. Novel and viable acetylcholinesterase target site for developing effective and environmentally safe insecticides. Current Drug Targets, n.4, 2012. DOI: http://doi.org/10.2174/138945012799499703

PARMAR, V. S.; JAIN, S. C.; BISHT, K. S.; JAIN, R.; TANEJA, P.; JHA, A.; TYAGI, O. D.; PRASAD, A. K.; WENGEL, J.; OLSEN, C. E.; BOLL, P. M.. Phytochemistry oh the genus Piper. Phytochemistry, v.46, n.4, p.597-673, 1997. DOI: http://doi.org/10.1016/S0031-9422(97)00328-2

PEREIRA, L. A.; SILVA, R. B. L.; GUIMARÃES, E. F.; ALMEIDA, M. Z.; MONTEIRO, E. C. Q.; SOBRINHO, F. A. P. Plantas medicinais de uma comunidade quilombola na Amazônia Oriental: aspectos utilitários de uma espécie das famílias Piperaceae e Solanaceae. Revista Brasileira de Agroecologia, v.2, n.2, p.1385-1388, 2007.

PINTO, T. J. A.; KANEKO, T. M.; OHARA, M. T.. Controle biológico de qualidade de produtos farmacêuticos, correlatos e cosméticos. 2 ed. São Paulo: Atheneu, 2003.

RAHMAN, A.; AL-REZA, S.M.; KANG, S.C. Antifungal activity of essential oil and extracts of Piper chaba Hunter against phytopathogenic fungi. Journal of the American Oil Chemists' Society, v.88, p.573-579, 2011. DOI: http://doi.org/10.1007/s11746-010-1698-3

RANASINGHE, L.; JAYAWARDENA, B.; ABEYWICKRAMA, K.. Fungicidal activity of essential oils of Cinnamomum zeylanicum (L.) and Syzygium aromaticum (L.) Merr and L.M Perry against crow rot and anthracnose pathogens isolated from banana. Microbiology, v.35, p.208-211, 2002. DOI: http://doi.org/10.1046/j.1472-765X.2002.01165.x

REIGADA, J. B.. Bioprospecção em espécies de Piperaceae. Dissertação (Mestrado em Química) - Universidade de São Paulo, São Paulo, 2009.

REIGADA, J. B.; TCACENCO, C. M.; ANDRADE, L. H.; KATO, M. J.; PORTO, A. L. M; LAGO, J. H. G.. Chemical constituents from Piper marginatum Jacq. (Piperaceae) - antifungal activities and kinetic resolution of (RS)-marginatumol by Candida antarctica lipase (Novozym 435). Tetrahedron: Asymmetry, v.18, p.1054-1058, 2007. DOI: http://doi.org/0.1016/j.tetasy.2007.05.006

RODRIGUES, E.; SCHWAN-ESTRADA, K. R. F.; STANGARLIN, J. R.; CRUZ, M. E. S.; FIORI-TUTIDA, A. C. G.. Avaliação da atividade antifúngica de extratos de gengibre e eucalipto in vitro e em fibras de bananeira infectadas com Helminthosporium sp. Acta Scientiarum Agronomy, Maringá, v.28, n.1, p.123-127, 2006. DOI: http://doi.org/10.4025/actasciagron.v28i1.1696

ROZWALKA, L. C.; LIMA, M. L. R. Z. D. C.; MIO, L. L. M.; NAKASHIMA, T.. Extratos, decoctos e óleos essenciais de plantas medicinais e aromáticas na inibição de Glomerella cingulata e Colletotrichum gloeosporioides de frutos de goiaba. Ciência Rural, v.38, p.301-307, 2008. DOI: http://doi.org/10.1590/S0103-84782008000200001

SANTOS, M. C.; OLIVEIRA JUNIOR, L. F. G.; OLIVEIRA, L. F. M.; CARVALHO, C. R. D.; GAGLIARDI, P. R.. Perfil volátil e potencial fungitóxico do hidrolato e extrato de sementes e folhas de Schinus terebinthifolius Raddi. Revista Ciência Agronômica, v.45, n.2, p.284-289, 2014.

SANTOS, P. R. D.; MOREIRA, D. L.; GUIMARÃES, E. F.; KAPLAN, M. A. C.. Essential oil analysis of 10 Piperaceae species from the Brazilian Atlantic forest. Phytochemistry, v.58, n.4, p.547-551, 2001. DOI: http://doi.org/10.1016/S0031-9422(01)00290-4

SCHWAN-ESTRADA, K. R. F.; STANGARLIN, J. R.; CRUZ, M. E. $\mathrm{S}$. Uso de plantas medicinais no controle de doenças de plantas. Fitopatologia Brasileira, v.28, p. 54-56, 2003.

SILVA, D. M. M. H.; BASTOS, C. N.. Atividade antifúngica de óleos essenciais de espécies de Piper sobre Crinipellis perniciosa, Phytophthora palmivora e Phytophthora capsici. Fitopatologia Brasileira, v.32, n.2, p.143-145, 2007. DOI: http://doi.org/10.1590/S0100-41582007000200008

SPADOTTO, C. A.; GOMES, M. A. F.; LUCHINI, L. C.; ANDRÉA, M. M.. Monitoramento do risco ambiental de agrotóxicos: princípios e recomendações. Embrapa Meio Ambiente. Documentos, Jaguariúna, v.42, p.1-24, 2004.

SRINIVASAN, K.. Black Pepper and its Pungent PrinciplePiperine: A Review of Diverse Physiological Effects. Critical Reviews in Food Science and Nutrition, v.47, p.735-748, 2007. DOI: http://doi.org/10.1080/10408390601062054

VENTUROSO, L. R.; BACCHI, L. M. A.; GAVASSONI, W. L.; CONUS, L. A.; PONTIM, B. C. A.; BERGAMIN, A. C. Atividade antifúngica de extratos vegetais sobre o desenvolvimento de fitopatógenos. Summa Phytopathologica, v.37, n.1, p.18-23, 2011. DOI: http://doi.org/10.1590/S0100$\underline{54052011000100003}$

WAGNER, H.; BLADT, S.. Plant drug analysis: a thin layer chromatography atlas. 2 ed. Berlim: Springer, 2001.

YAMAGUCHI, L. F.; LAGO, J. H. G.; TANIZAKI, T. M.; MASCIO, P. D.; KATO, M. J.. Antioxidant activity of prenylated hydroquinone and benzoic acid derivatives from Piper crassinervium Kunth. Phytochemistry, v.67, p.1838-1843, 2006. DOI: http://doi.org/10.1016/j.phytochem.2006.03.001

YUNCKER, T. G.. The Piperaceae of Brazil: I-Piper-Group I, II, III, IV. Hoehnea, v.2, p.19-366, 1972.

A CBPC - Companhia Brasileira de Produção Científica (CNPJ: 11.221.422/0001-03) detém os direitos materiais desta publicação. Os direitos referem-se à publicação do trabalho em qualquer parte do mundo, incluindo os direitos às renovações, expansões e disseminações da contribuição, bem como outros direitos subsidiários. Todos os trabalhos publicados eletronicamente poderão posteriormente ser publicados em coletâneas impressas sob coordenação da Sustenere Publishing, da Companhia Brasileira de Produção Científica e seus parceiros autorizados. Os (as) autores (as) posteriormente ser publicados em coletâneas impressas sob coordenação da Sustenere Publishing, da Companhia Brasileira de Produção Científica e seus parce
preservam os direitos autorais, mas não têm permissão para a publicação da contribuição em outro meio, impresso ou digital, em português ou em tradução. 